\title{
Investigation on fretting wear behavior of 690 alloy in water under various temperatures
}

\author{
X. Mi ${ }^{1}$, Z. B. Cai ${ }^{1}$, X. M. Xiong ${ }^{1}$, H. Qian ${ }^{2}$, L. C. Tang ${ }^{2}$, Y. C. Xie ${ }^{2}$, \\ J. F. Peng ${ }^{1}$, Min-hao Zhu ${ }^{1 * 1}$ \\ 1. Key Laboratory of Advanced Materials Technology, Ministry of Education, Southwest Jiaotong University, \\ Chengdu, 610031, China.
}

2. Shanghai Nuclear Engineering Research and Design Institute, Shanghai, 200233, China.

\begin{abstract}
:
The aim of this paper is to assess the effect of water temperature (room temperature - RT, $60{ }^{\circ} \mathrm{C}$ and $90{ }^{\circ} \mathrm{C}$ ) on fretting wear behavior of 690 alloy tubes against 405 stainless steel plates, and compare it with fretting in dry condition. Due to the lubrication effect, the presence of a thin water film likely precluded the metal-metal contact, and resulted in less wear. During the fretting process, water also washed the wear particles away from the contact zone leading to a decrease of abrasive wear. Consequently, the wear scars showed "U" shape profile along the fretting direction in water, while "W" shape in air.
\end{abstract}

Keywords: Fretting, 690 alloy, Temperature effect, Wear mechanism.

\section{Introduction}

Due to flow-induced vibration, steam generator tubes in pressurized water reactor are expected to be subject to small amplitude oscillatory motion against their supports (or anti-vibration bars) [1]. The value of oscillation frequency and relative displacement of steam generator tubes were reported to reach up to $30 \mathrm{~Hz}$ and $200 \mu \mathrm{m}$, respectively [2-3]. Moreover, the tubes are operated in such an aggressive condition at temperature up to $325^{\circ} \mathrm{C}$ [4]. The need of understanding and predicting the failure of steam generator tubes attracts the attention of researchers, due to its significant economic and safety impacts. As alternative to Inconel 600 alloy, Inconel 690 alloy has recently been used as the material of steam generator tubes in nuclear plants [5]. This is mainly owing to its combined

1 *.Corresponding author. Tel.: +86 2887600715; fax: +86 2887601342 .

E-mail addresses: zhuminhao@home.swjtu.edu.cn, zhuminhao@swjtu.cn. 
superior stress corrosion cracking resistance, and excellent mechanical characteristics at high temperature and in high pressure water. Although many detailed studies have been carried out on fretting fatigue [6-7], corrosion behavior [8-9] and stress corrosion cracking in simulated PWR primary water [10-12], they rarely revealed relevant information on fretting wear of Inconel 690 alloy in PWR secondary water. The fretting action possibly results in contact surfaces wear by detachment of particles, and contact fatigue by rapid crack nucleation and propagation, leading to premature catastrophic failures [13]. Hence, it was necessary to pay more attention to fretting wear of steam generator tubes.

More work was reported in the open literatures on the effect of various test conditions on wear in air [2, 14-17], while less studies treated the fretting wear behaviors under wet condition. The work on fretting wear of 690 alloy for different level of $\mathrm{pH}$ environment have demonstrated that the friction coefficient reached the maximum at $\mathrm{pH}$ value of 7 due to different surface states at different $\mathrm{pH}$ values [18]. Zhang et al. found that abrasive wear and delamination were the main mechanisms of Inconel 690 in distilled water. When fretted in hydrazine solution, cracks accompanied by abrasive wear and delamination dominated wear mechanisms were observed [19]. To address the problem of fretting corrosion of heat exchanger tubes, ferritic-martensitic steel T91 and austenitic steel 1.4970 were tested in liquid lead. [3]. Most of fretting wear experiments were carried out using ball-on-plate [20-22] or ball-on-tube, and only very limited data are available on fretting wear of tube/plate contact configuration.

The present work, therefore, was initiated with the objective of generating relevant design data on the fretting wear behavior of 690 alloy tubes in simulated PWR secondary water, at different temperatures. The fretting wear tests were carried out for tube/plate contact configuration. To distinguish wear mechanisms, the worn surfaces and the morphology of cross-sections of the wear scars were observed through SEM, EDX and EPMA. Moreover, a particular debris cleaning method was used to remove wear particles of worn 690 alloy tube effectively in order to estimate exact wear volume [23].

\section{Experimental set-up}

\subsection{The test specimens}

The specimens selected in this study were 690 alloy $(R \mathrm{a}=0.4 \mu \mathrm{m})$ and 405 stainless steel $(R \mathrm{a}=0.6 \mu \mathrm{m})$, that are widely used in nuclear industry - for generator tubes and anti-vibration bars, 
respectively. The microstructure of 690 alloy is presented in Fig. 1. The chemical composition and mechanical properties of the tested materials are listed in Table 1 and Table 2, respectively. The details of configuration parameters of the test specimens were reported elsewhere [23]. 690 alloy was cut from an as-received generator tube made by Baosteel. For each test samples had been ultrasonically cleaned in ethyl alcohol and then dried with hot compressed air, prior to being assembled on the tribometer.

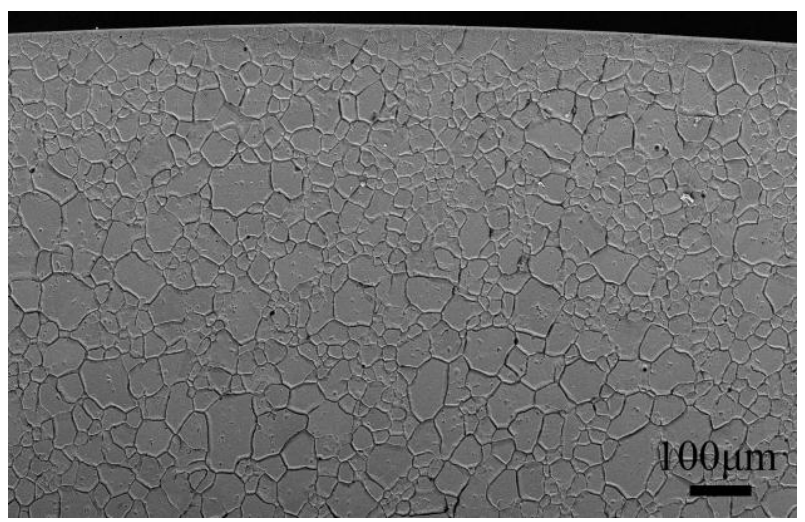

Fig. 1. Mircostructure of 690 alloy.

Table 1 Chemical composition of 690 alloy and 405 stainless steel

\begin{tabular}{cccccccccc}
\hline $\begin{array}{c}\text { Chemical } \\
\text { composition }\end{array}$ & $\mathrm{Ni}$ & $\mathrm{Cr}$ & $\mathrm{Fe}$ & $\mathrm{Al}$ & $\mathrm{C}$ & $\mathrm{Si}$ & $\mathrm{Mn}$ & $\mathrm{S}$ & $\mathrm{P}$ \\
\hline 690 alloy & $\geq 58.0$ & $28.5-31.0$ & $9.0-11.0$ & $\leq 0.40$ & $0.015-0.025$ & $\leq 0.50$ & $\leq 0.50$ & $\leq 0.003$ & $\leq 0.015$ \\
\hline 405 stainless & $\leq 0.60$ & $11.5-14.5$ & Bal. & $0.10-0.30$ & $\leq 0.08$ & $\leq 1.00$ & $\leq 1.00$ & $\leq 0.030$ & $\leq 0.040$ \\
\hline
\end{tabular}

Table 2 Mechanical properties of 690 alloy and 405 stainless steel

\begin{tabular}{cccc}
\hline Mechanical properties & Hardness (HB) & Yield strength (MPa) & Elasticity modulus (GPa) \\
\hline 690 alloy & - & 336.5 & 208 \\
\hline 405 stainless & 160 & 373 & 201 \\
\hline
\end{tabular}

\subsection{Fretting wear test conditions}

The experimental investigation was performed on a fretting wear test rig with a contact configuration of tube-on-plate, as shown in Fig. 2. The direction of motion was perpendicular to the axis of the tube. To achieve elevated temperature in water environment, the fretting wear tester was 
connected to a water supplying loop system in these experiments, special heaters were used to heat the water supplied to the water tank through the IN hole. The water left through the OUT hole on the opposite side in order to maintain the water level. The tribological tests have been carried out in water at various temperature of RT (room temperature), $60{ }^{\circ} \mathrm{C}$ and $90{ }^{\circ} \mathrm{C}$, with a deviation of $\pm 2 \%$. The displacement amplitudes of fretting wear were controlled at $100 \mu \mathrm{m}$ and $200 \mu \mathrm{m}$. Other parameters were kept unchanged for all tests; a frequency of $5 \mathrm{~Hz}, 10^{5}$ fretting cycles and a normal load of $40 \mathrm{~N}$ (equivalent to a maximal Hertz contact stress of $23.074 \mathrm{MPa}$ ). In this work, the test solution was simulated PWR secondary water (deionized water mixed with few ammonia water). The $\mathrm{pH}$ of the test solution was 9.0 to 9.1 at RT, and the conductance was approximately 3.0. For the sake of simplicify, the solution environment will be referred to as the water environment in this paper.

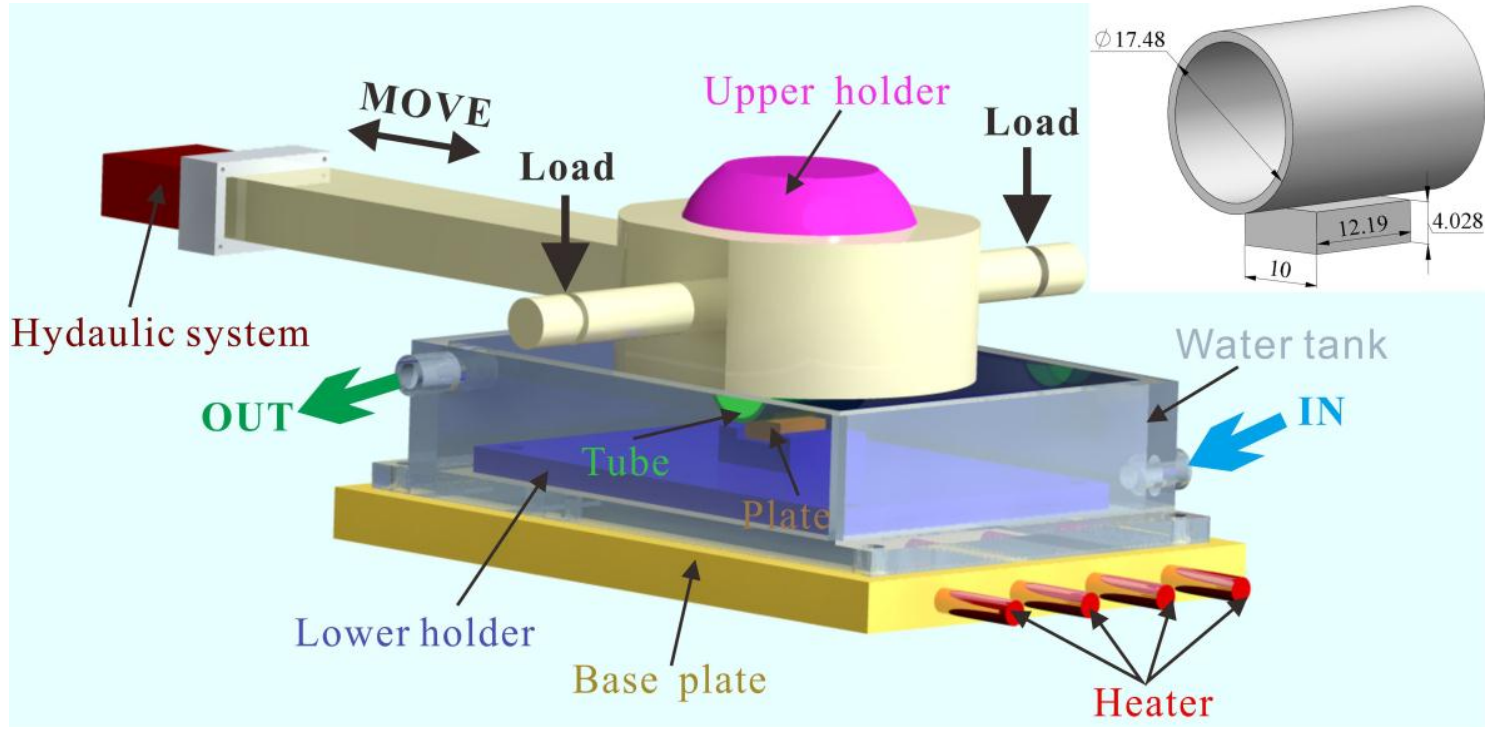

Fig. 2. Schematic diagram of fretting wear tester.

\subsection{Surface analysis}

After the fretting wear tests, in order to reveal the wear mechanisms, the specimens were examined using SEM, EDX and EPMA to obtain imformation of morphologies and surface chemical compositions. Subsequently, a 3D optical microscope (Bruker ContourGT-I) was used to acquire the profile of the wear scars. Following the wear scar morphology examination and surface chemical analysis, the specimens were cleaned through a special chemistry cleaning method (APAC) to remove wear debris. Finally, the wear volume was measured again using a 3D optical microscope. The cleaning steps of APAC consisted of four steps. After cleaned with ethyl alcohol ultrasonically, 
specimens were put into, successively, approximately boiling mixture of permanganate and sodium hydroxide, and the solution of citric acid diammonium hydrogen. Finally, specimens were cleaned by ultrasonication in ethyl alcohol and then dried with the hot compressed air.

\section{Results}

\section{1. $F_{t}-D$ curves and friction coefficient}

As shown in Fig. 3, the shape of all the $F_{\mathrm{t}} D$ plots to be close to parallelogram, indicating that all the tests were in the running state of gross slip, i.e. in the gross slip regime. The gross slip generally resulted in larger amounts of material removal and debris formation. In Fig. 3, the initial friction force was relatively low and reached a peak around 10000 cycles above $60{ }^{\circ} \mathrm{C}$

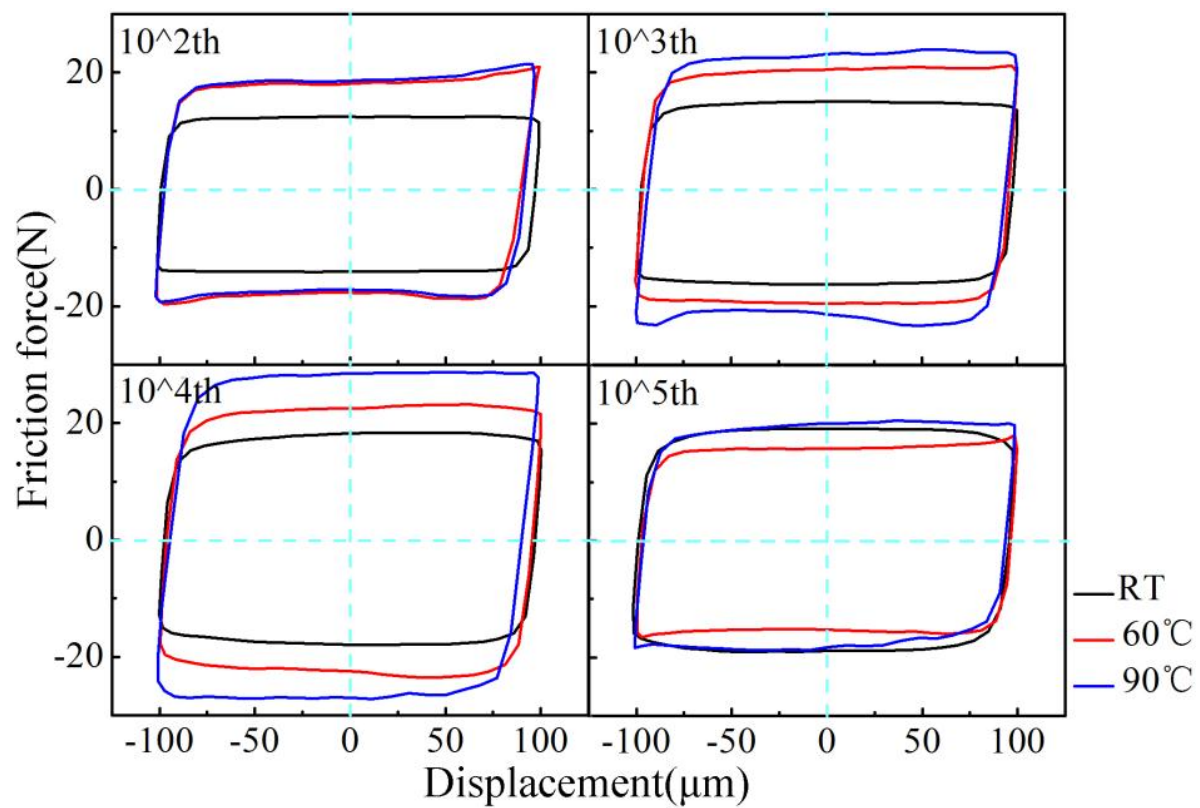

Fig. 3. Variation of $F_{\mathrm{t}}-D$ curves as function of number of cycle in water, $D=100 \mu \mathrm{m}$.

As indicated in Fig. 4, the values of friction coefficients were about 0.4 at the end of the tests in water at various temperatures. However the friction coefficient curves presented very different evolution. At RT, the change of friction coefficient with the number of cycles exhibited five stages (run-in stage, quickly ascending stage, peak stage, descending stage, slowly increasing stage). At first, the friction coefficient was relatively low due to the existence of surface adsorption and pollution films. Then the friction coefficient rose sharply due to the metal-to-metal contact and material adhered after the run-in stage. In the meanwhile, the wear debris were generated and participated in bearing the load, leading to the decrease of friction coefficient after the friction coefficient reached the peak stage. With the increase of the number of cycles, the wear induced the linear contact transformed to surface contact. Consequently, the contact was not just an initial asperity-to-asperity 
contact, but rather a plane-to-plane contact, which led to higher friction coefficient. Thus in the last stage, the friction coefficient increased gradually.

Water also caused wear debris to be dragged away from the contact zone, this external effect played an important role during the evolution of the friction coefficient after the debris formation, i.e. after the peak stage. After approximately 25000 cycles, a large difference was observed between the low temperature environment (RT) and the high temperature environment $\left(60{ }^{\circ} \mathrm{C}\right.$ and $\left.90{ }^{\circ} \mathrm{C}\right)$. Compared to RT, the temperature above $60{ }^{\circ} \mathrm{C}$ corresponded to high rate of oxidation (the analysis to be presented in subsequent sections), which led to a load-bearing oxidative layer formed in the fretting zone, and therefore, the decrease of the friction coefficient. Therefore, the phenomenon of dropping down of friction coefficients can be explained by the antifriction nature of the oxidative layer, the debris removing effect, and the lubrication effect of water that have transformed the main roles between the contact interfaces after 25000 cycles at high temperature. As shown in Fig. 4, the friction coefficient curve for the RT began to drop down at end of the test. This was also the result of the combined effects of surface oxidative layer, debris removing and lubrication action.

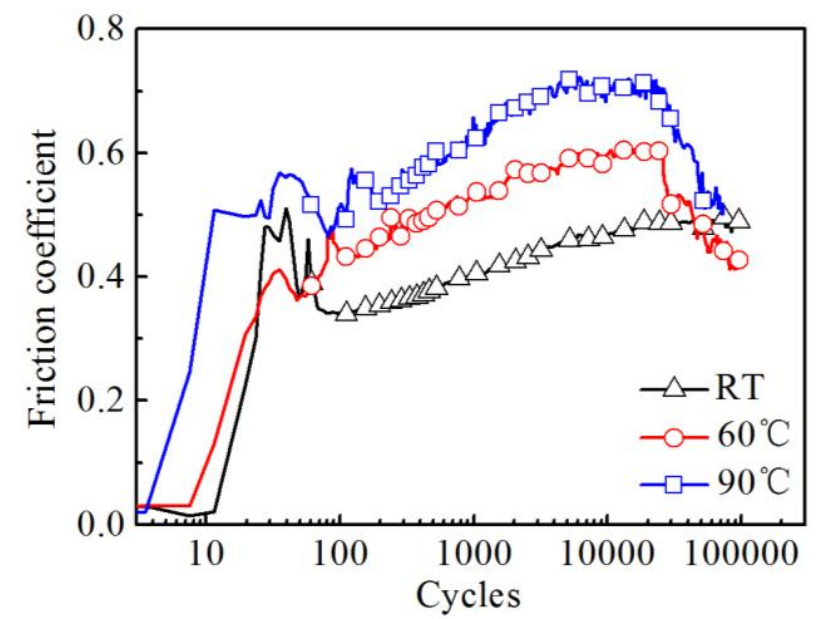

Fig. 4. Friction coefficients in various temperatures water, $D=100 \mu \mathrm{m}$.

\subsection{Morphologies of worn surfaces}

Fig. 5 shows the SEM micrographs of typical wear scars of tube specimens in water. Before the APAC, at RT, the worn surface was covered with numerous grooves paralleled to the sliding direction and some detachments, indicative of abrasive wear and delamination [Fig. 5(a)]. Besides, the micro-pitting by delamintion was more obvious with increasing temperature. Above $60{ }^{\circ} \mathrm{C}$, the wear track was surrounded by an accumulation of loose debris, with pockets of debris trapped within 
the contact region [Fig. 5(b)-(c)], which agreed with the decreasing of friction coefficient (Fig. 4). Additionally, some cracks and delamination still occurred on all worn surfaces, especially at $60{ }^{\circ} \mathrm{C}$ High content of oxygen was observed above $60{ }^{\circ} \mathrm{C}$ through the EDX analysis (as shown in Table 3), which was associated with high oxidation. In general, the most severe damage was at $90{ }^{\circ} \mathrm{C}$ because of the delamination of material. In table $3,22.32 \%$ oxygen (Point A) indicated that relatively lower oxidation occurred between the contact interfaces at RT. This is why the friction coefficient curve did not drop down greatly at the end of the test. After the APAC, there were no wear debris covering cleaned surfaces [Fig. 5(d)], hence, it can be speculated that APAC removed wear particles effectively.
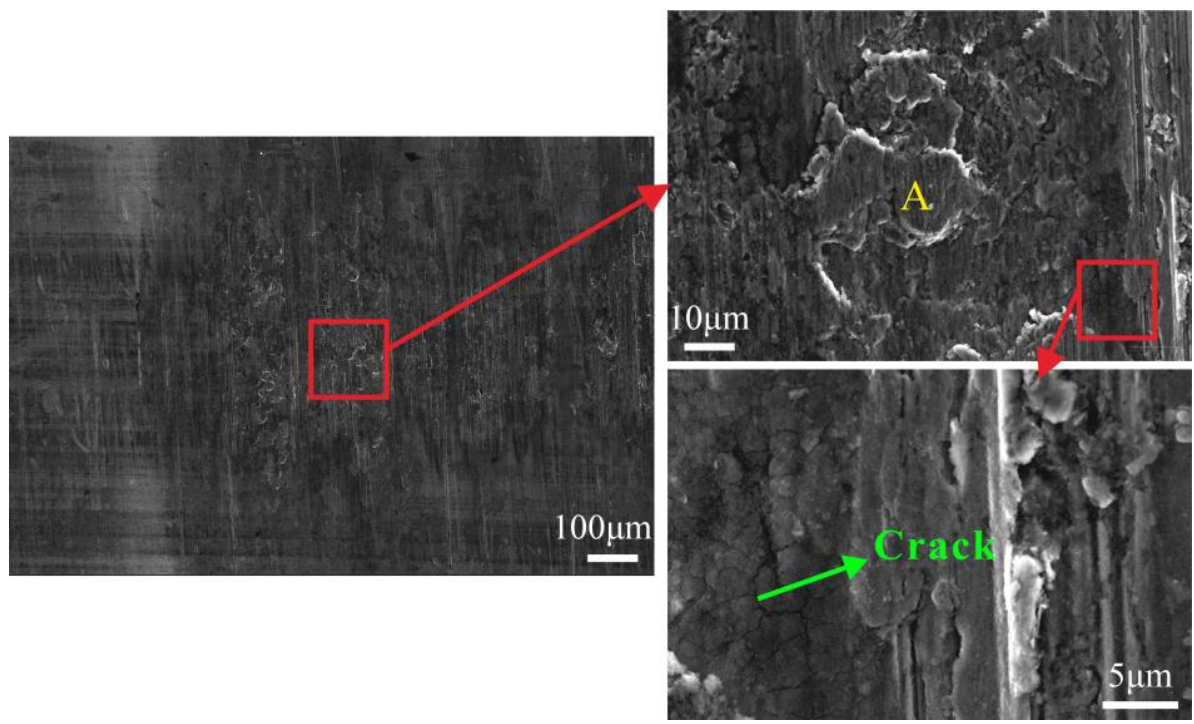

(a) RT, before the APAC

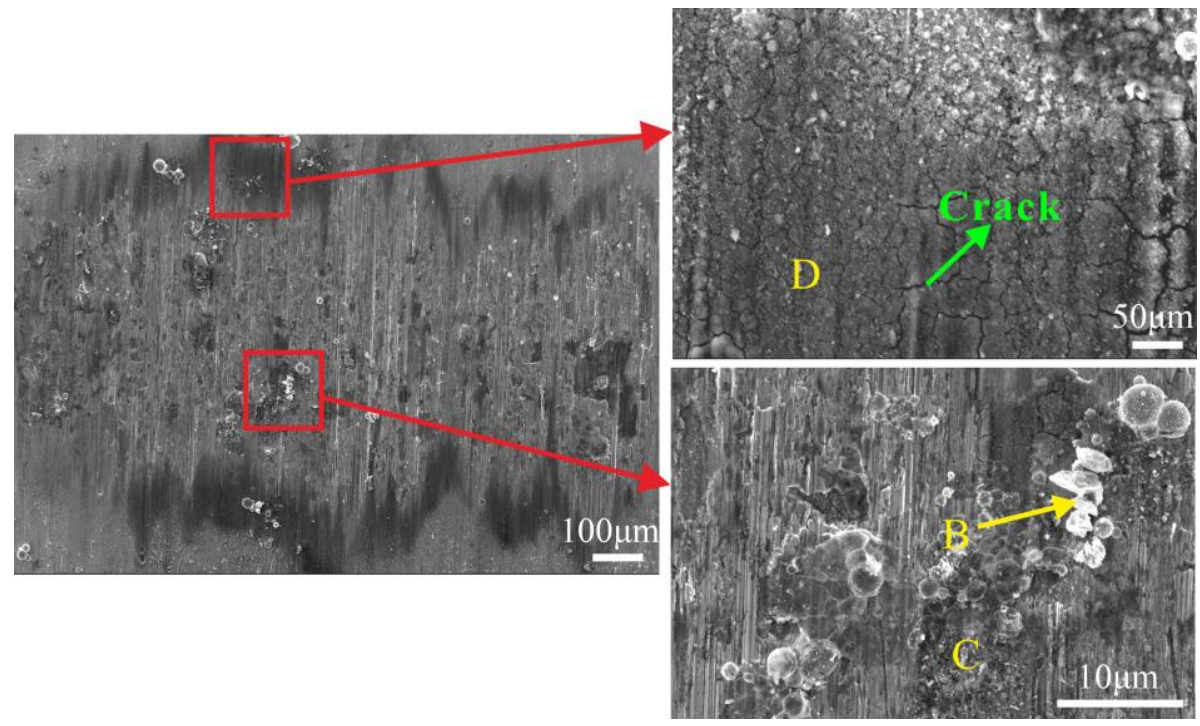


(b) $T=60^{\circ} \mathrm{C}$, before the APAC

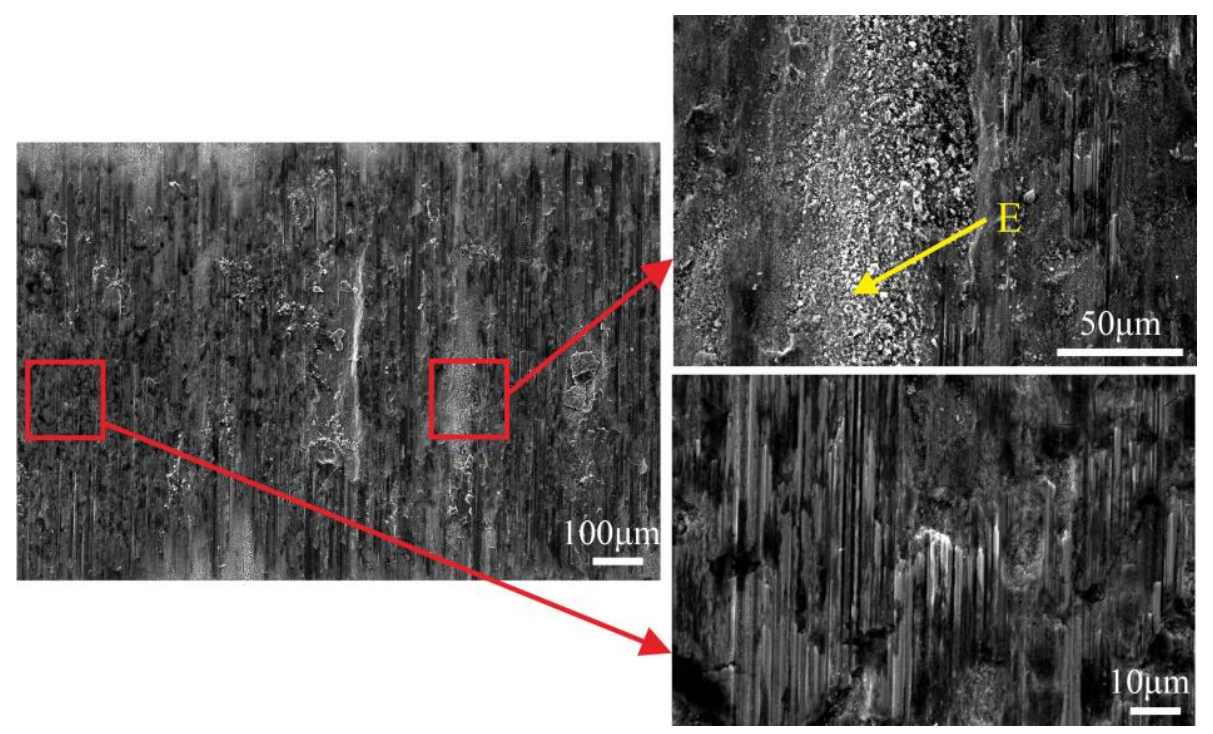

(c) $T=90^{\circ} \mathrm{C}$, before the APAC
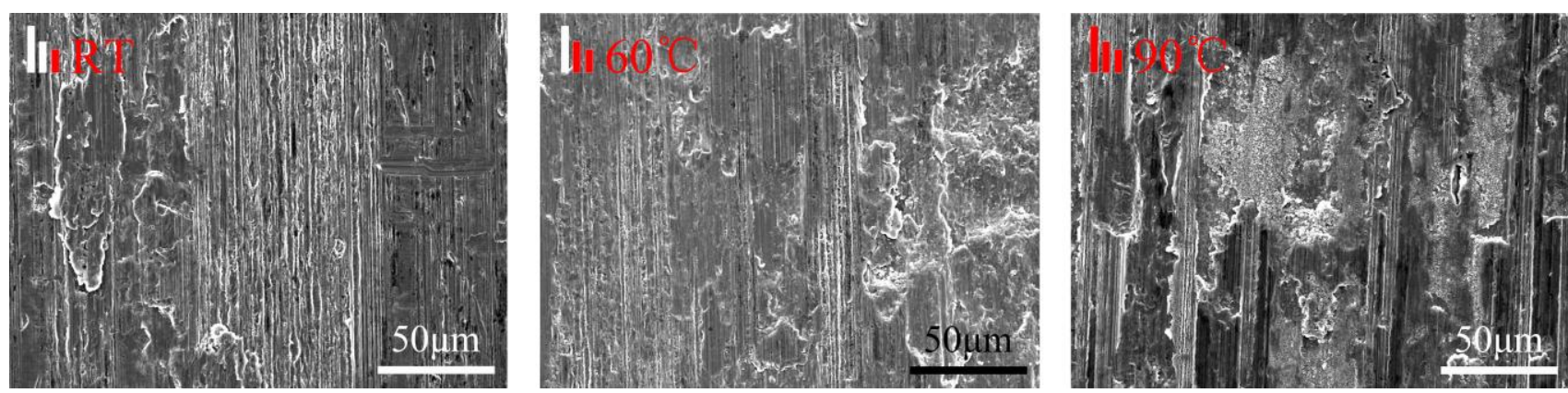

(d) RT to $90{ }^{\circ} \mathrm{C}$, after the APAC

Fig. 5. SEM micrographs of the worn tubes in water, $D=100 \mu \mathrm{m}$.

Table 3 EDX results of site A-E in Fig. 5 (at. \%).

\begin{tabular}{cccccc}
\hline Element & $\mathrm{A}$ & $\mathrm{B}$ & $\mathrm{C}$ & $\mathrm{D}$ & $\mathrm{E}$ \\
\hline $\mathrm{O}$ & 22.32 & 72.43 & 46.13 & 56.28 & 54.23 \\
\hline $\mathrm{Cr}$ & 18.41 & 5.54 & 16.39 & 13.93 & 13.11 \\
\hline $\mathrm{Fe}$ & 19.83 & 18.36 & 10.45 & 9.67 & 14.23 \\
\hline $\mathrm{Ni}$ & 39.44 & 3.67 & 25.97 & 19.00 & 18.02 \\
\hline
\end{tabular}

The SEM images of worn plates are presented in Fig. 6, and all contact zones displayed shapes of near rectangle. Comparing the results obtained for displacement amplitude of $100 \mu \mathrm{m}$ [Fig. 6(a)] with $200 \mu \mathrm{m}$ [Fig.6(c)], the width of contact zone was enlarged and covered more loose wear particles that occurred at the edge of contact zone with the increase of displacement amplitude. The micro-pitting caused by delamination under $200 \mu \mathrm{m}$ were larger than that of $100 \mu \mathrm{m}$. Under $200 \mu \mathrm{m}$ 
[Fig. 6(b)-(d)], the contact zone increased from RT to $60{ }^{\circ} \mathrm{C}$ and decreased slightly from $60{ }^{\circ} \mathrm{C}$ to $90{ }^{\circ} \mathrm{C}$, due to the maximum wear particles produced at $90{ }^{\circ} \mathrm{C}$. The removal of the wear particles, at the edge of contact zone, from the contact interfaces [Fig. 6(c)-(d)] possibly resulted in decreasing friction force after approximately 25000 cycles above $60{ }^{\circ} \mathrm{C}$ (Fig. 4). During the course of the test, the debris formed from the contact interfaces were both entrapped within and ejected from the contact zone. It was obvious that more wear particles were observed at $90{ }^{\circ} \mathrm{C}$ than that at RT. At RT, large amount wear particles were expelled from the contact zone during the test, while small part remained. This resulted in abrasive wear and increase in friction [Fig. 6(a)-(b)]. At $90^{\circ} \mathrm{C}$, even wear particles were ejected but not enough, as they partly accumulated at the edge of contact zone.

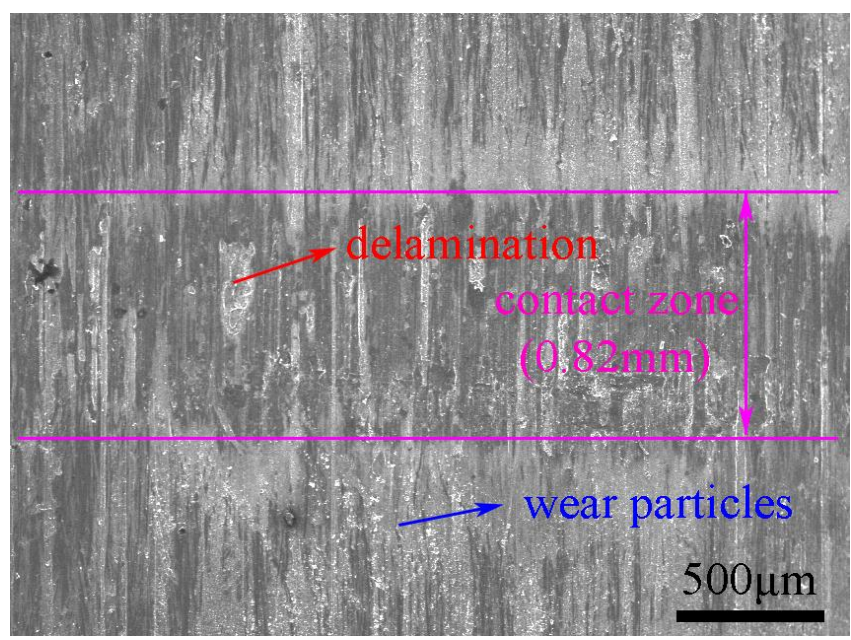

(a) $D=100 \mu \mathrm{m}, T=60^{\circ} \mathrm{C}$

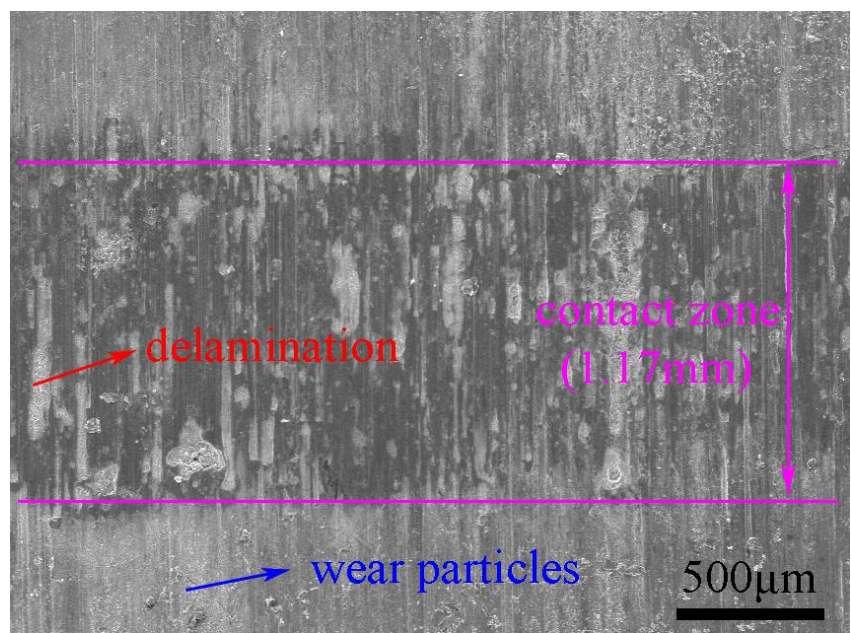

(c) $D=200 \mu \mathrm{m}, T=60{ }^{\circ} \mathrm{C}$

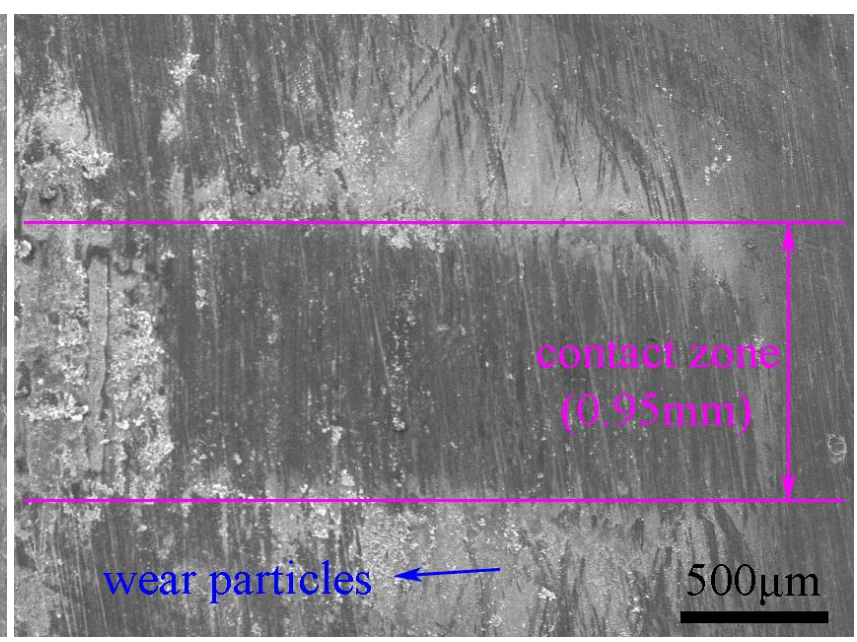

(b) $D=200 \mu \mathrm{m}$, RT

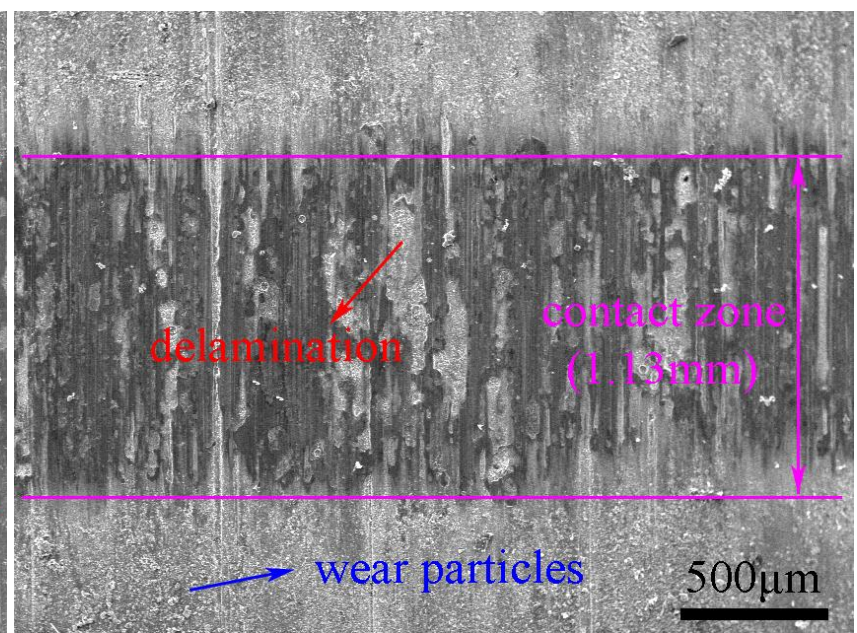

(d) $D=200 \mu \mathrm{m}, T=90{ }^{\circ} \mathrm{C}$

Fig. 6. The SEM micrographs of the worn plate in water.

Fig. 7 shows the profiles of the fretting tube scars along the fretting direction before the APAC. 
The profiles shown in figure were subtracted the original tube profile after measuring. As shown in Fig.7 (a), along the fretting direction of the wear scar, the maximum wear depth appeared at the center of the contact zone, resembling a "U" shape. Besides, the edge of the wear scar was the highest above $60{ }^{\circ} \mathrm{C}$ under $200 \mu \mathrm{m}$, corresponding to the accumulated wear debris (Fig. 5 and Fig. 6). Furthermore, increasing temperature and displacement caused the elevation of wear depth. However, it was obvious that displacement had more significant effect on wear depth than temperature. As seen in Fig. 7(b), the profile resembled a "W" shape in air, while a "U" shape occurred in water. Under the same experimental conditions, the wear depth and width of wear scar in air were much larger than those in water. Overall, the damage of specimens in water was slightly less than that in air.

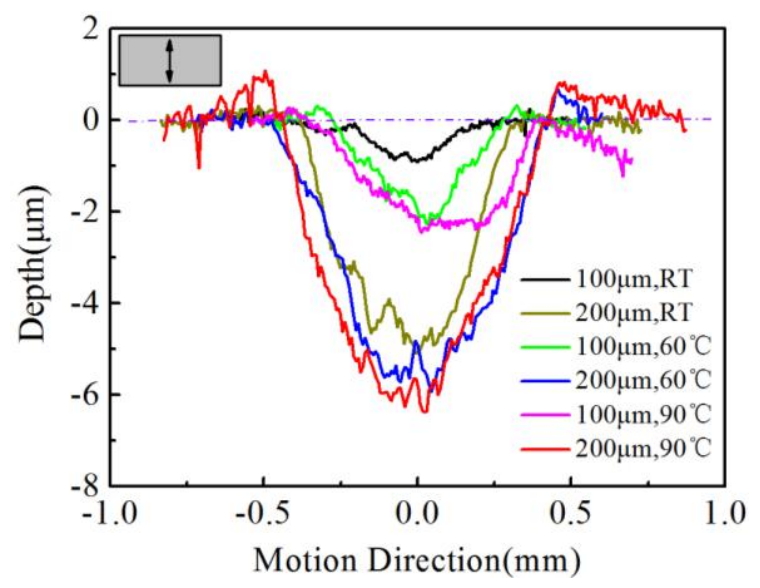

(a) In water

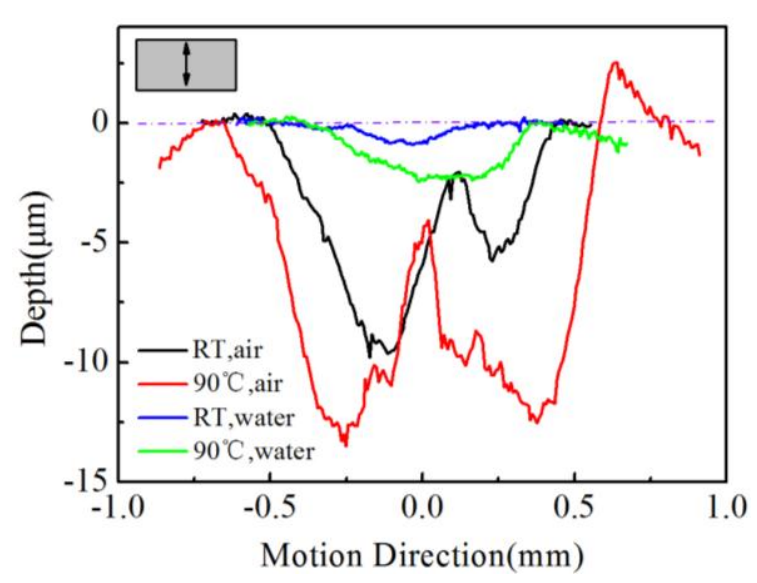

(b) $D=100 \mu \mathrm{m}$

Fig. 7. The profile micrographs of the fretting tube scars before APAC clean.

Fig. 8 is the 3D-profile micrographs of the fretting tube scars after the APAC cleaning in water. The worn tubes, whose maximum wear depth appeared at the edge of length directions, had the widest scar at $90{ }^{\circ} \mathrm{C}$. Because of the cleaning process, the wear zone was completely exposed. Therefore, these results were accurate for determining the width of wear scar and the wear depth. The width of the worn scar and wear depth increased gradually with increasing temperature [Fig. 8(a)-(c)]. Comparing the results obtained for a displacement amplitude of $100 \mu \mathrm{m}$ [Fig. 8(c)] with those for $200 \mu \mathrm{m}$ [Fig. 8(d)], the maximum wear depth and width of wear scar occurred under 200 $\mu \mathrm{m}$. 


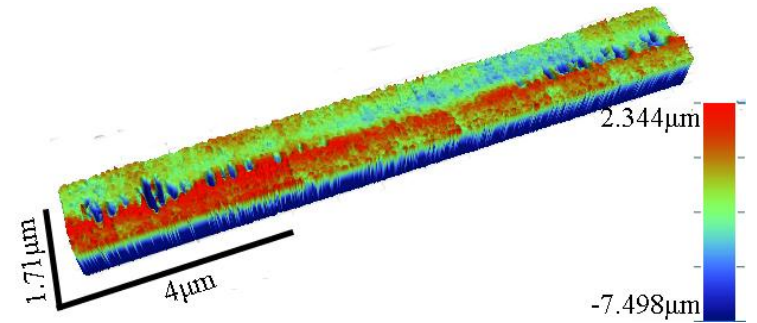

(a) $D=100 \mu \mathrm{m}$, RT

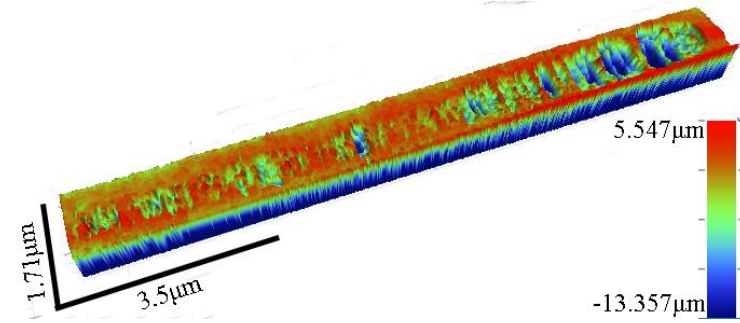

(c) $D=100 \mu \mathrm{m}, T=90{ }^{\circ} \mathrm{C}$

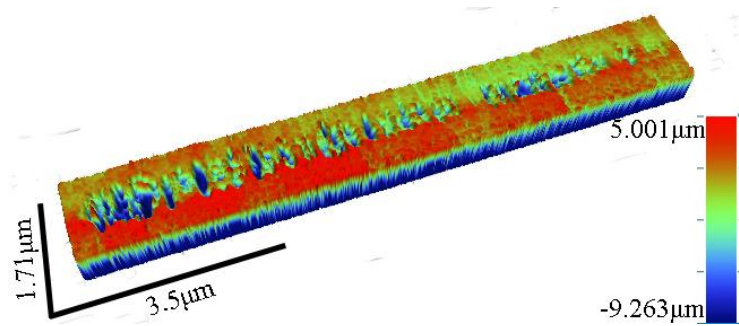

(b) $D=100 \mu \mathrm{m}, T=60{ }^{\circ} \mathrm{C}$

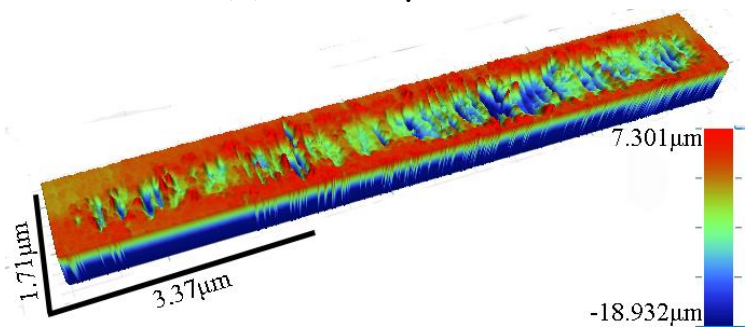

(d) $D=200 \mu \mathrm{m}, T=90^{\circ} \mathrm{C}$

Fig. 8. The 3D-profile micrographs of the fretting tube scars after APAC clean in water.

Fig. 9 shows the morphologies of the cross-section of the tube wear scar at $90{ }^{\circ} \mathrm{C}$ and $100 \mu \mathrm{m}$. A minute delamination crack was observed in the sub-surface layer paralleled to the surface. Sub-surface cracks were initiated due to surface fatigue effect, which eventually linked the surface crack, leading to detachment and removal of material. Water played the role not only as a lubricant to decrease wear but also as an external effect to drag wear debris away from contact interfaces. Therefore, it was difficult to form a debris layer, as compared with air. Meanwhile, it was obvious that expelled wear particles accumulated at the edge of the contact zone.

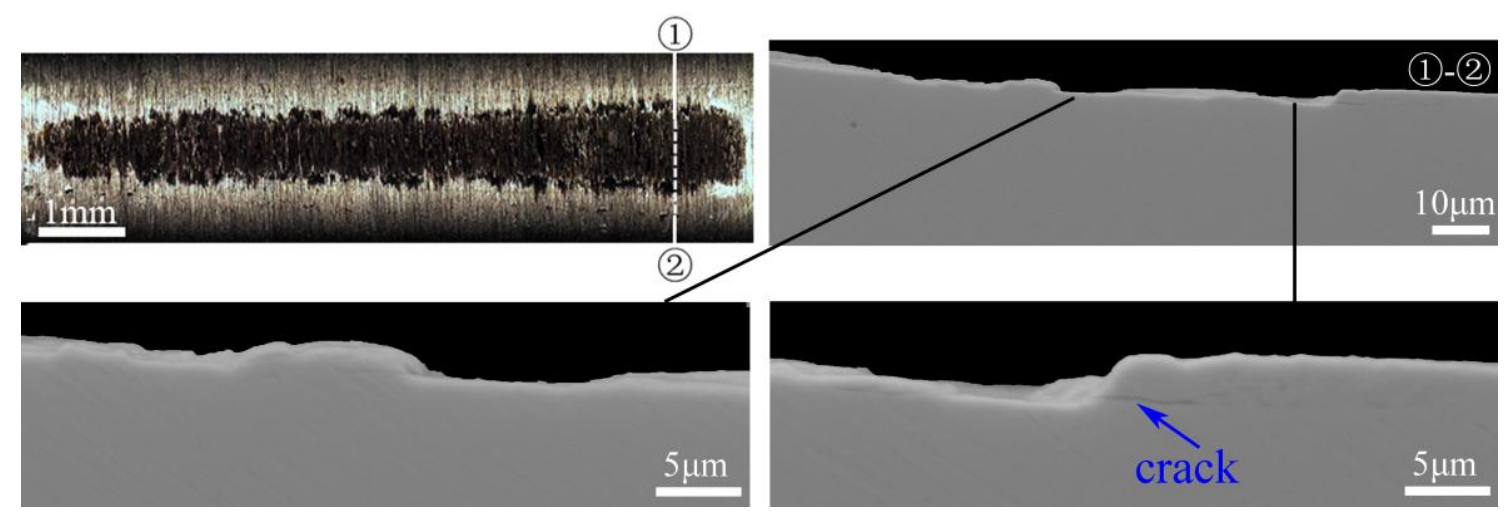

Fig. 9. Morphologies of the cross-section of the worn tubes in water; $T=90{ }^{\circ} \mathrm{C}, D=100 \mu \mathrm{m}$.

\subsection{Surface chemical composition analysis}

In water at $90{ }^{\circ} \mathrm{C}$, the chromium, iron, nickel and oxygen mass concentrations were measured by EPMA at three typical locations in the worn surface of 690 alloy tube [Fig. 10(a)]. Positions (1) 
and (2) were located in contact zone, and position (3) was posited in unworn zone. As positions (1)and (3) showed similar concentration of main elements, it can be concluded that position (1)almost remained unoxidized metal. On the other hand, position (2)was oxide, as demonstrated by the high content of oxygen and iron. As shown in Fig. 10(b), the partial worn region showed high content of oxygen, possibly remained wear particles corresponding to the black area in Fig. 10(a). In general, the content of iron and oxide were higher in partial worn area than that of unworn area.
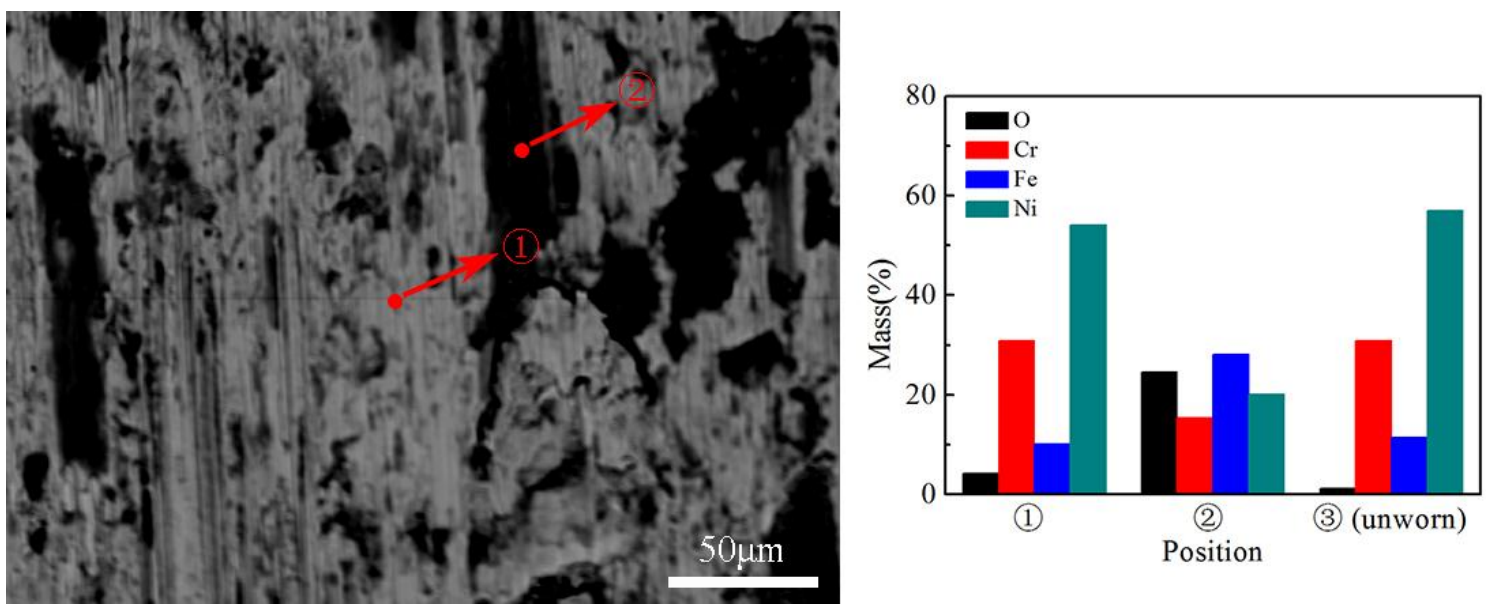

(a)
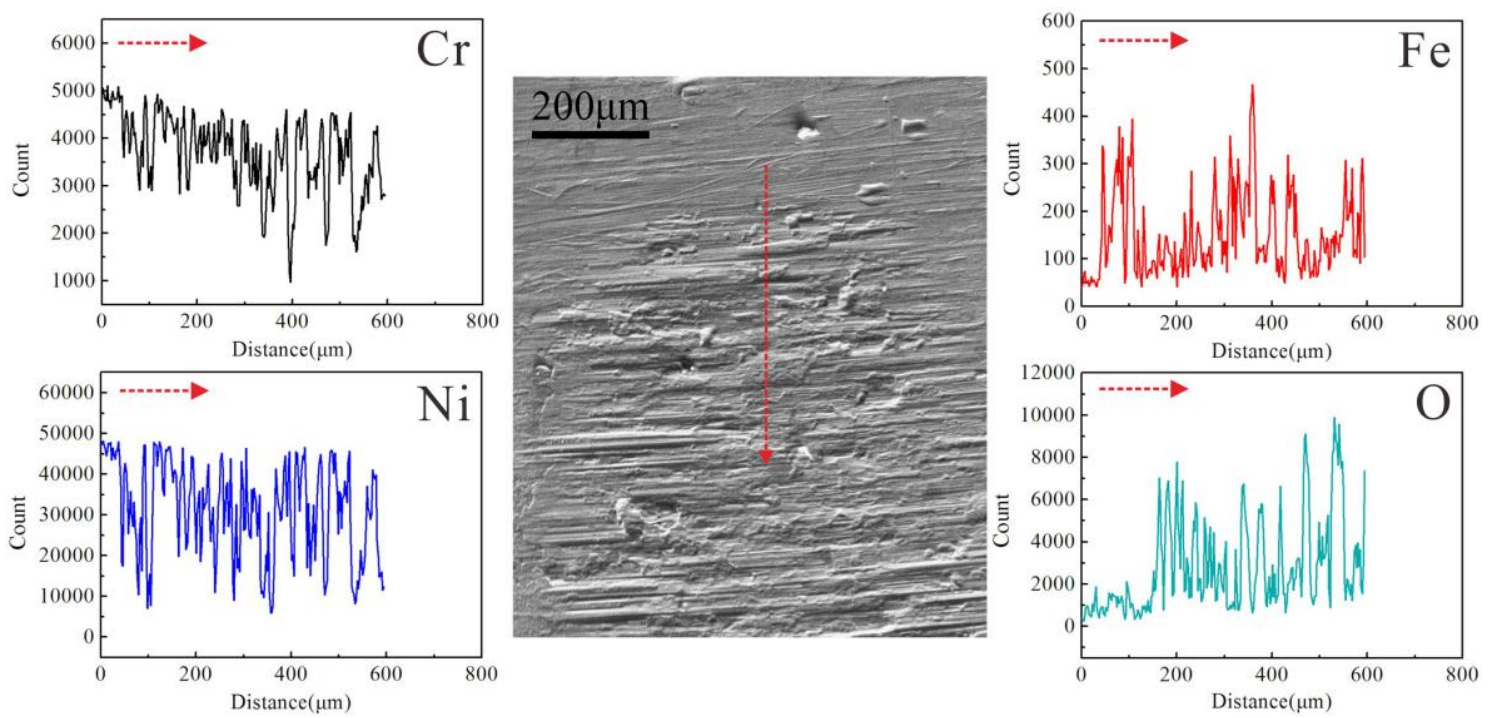

(b)

Fig. 10. EPMA analysis on worn surface of 690 alloy tube in water, $T=90{ }^{\circ} \mathrm{C}, D=100 \mu \mathrm{m}$.

Fig. 11 shows the EPMA results of $\mathrm{O}$ and $\mathrm{Ni}$ element distribution on 405 stainless steel surfaces after the test. As supported by the EPMA elemental mapping [Fig. 11(a)], the fretted area was characterized by almost completely $\mathrm{O}$ and partially Ni concentration at RT. In contrast, at $90{ }^{\circ} \mathrm{C}$, a homogeneous distribution of $\mathrm{O}$ and $\mathrm{Ni}$ were detected in fretted area [Fig. 11(b)]. Additionally, it was 
obvious that high content of $\mathrm{O}$ was counted due to accumulated wear debris. Coinciding with the previous results in Fig. 6 and Fig. 10, O enriched area in the fretted area was wear particles mainly from the plate, while Ni enriched zone was the material removed from the contacting tube.
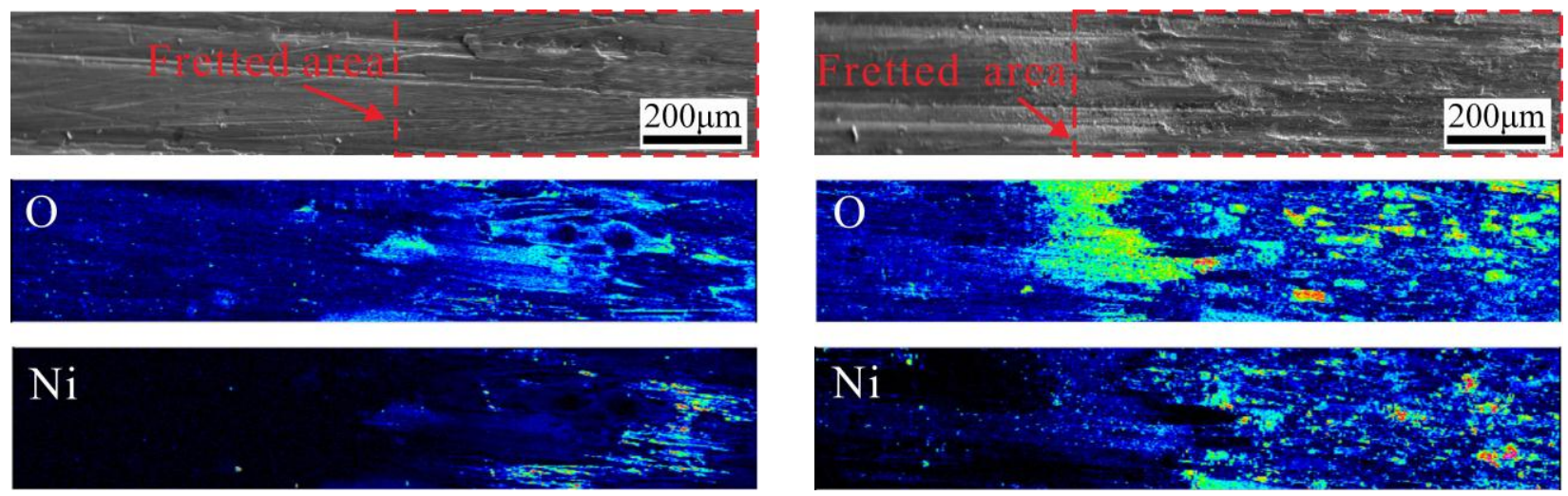

(a) RT

(b) $T=90^{\circ} \mathrm{C}$

Fig.11. EPMA elemental mapping of the fretted surfaces of 405 stainless steel plate specimens, $D=200 \mu \mathrm{m}$.

\subsection{Wear volume}

The volume loss of 690 alloy tube is presented in Fig. 12(a), which shows the mean value and the standard deviation for each test condition in water. The wear volume was approximately proportional to the temperature because of the increase of the micro-pitting wear as shown in Fig. 5 and Fig. 6. As expected, the wear volume increased for larger displacement, essentially because of the larger sliding distance, which resulted in wider fretting zone. As shown in Fig. 12(b), the wear volume was fairly less compared with that in air. In comparison, the wear volume in air was at least 11 times larger than that of in water, which can be attributed to abrasive wear and excessive oxidation reaction in air. It is also obvious that the water acted as an effective lubricant that protects mating surfaces from being damaged. 


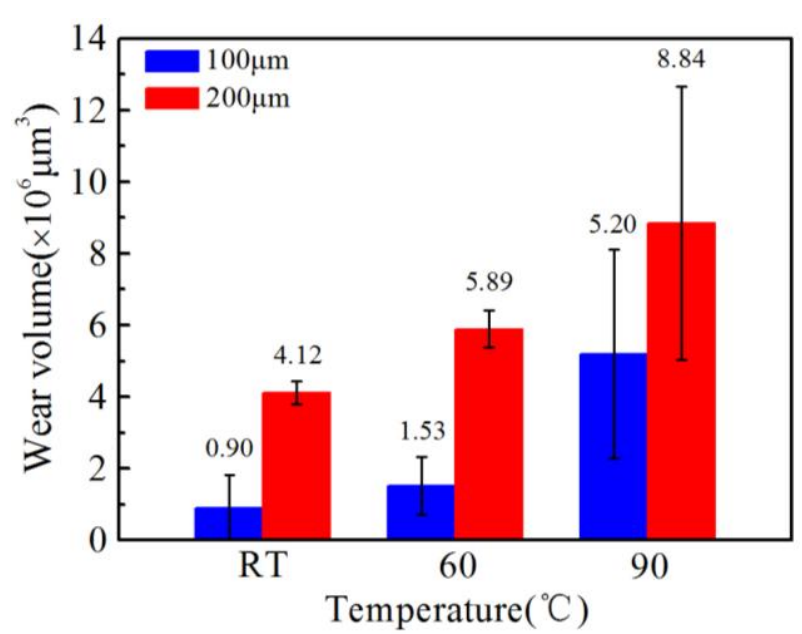

(a)

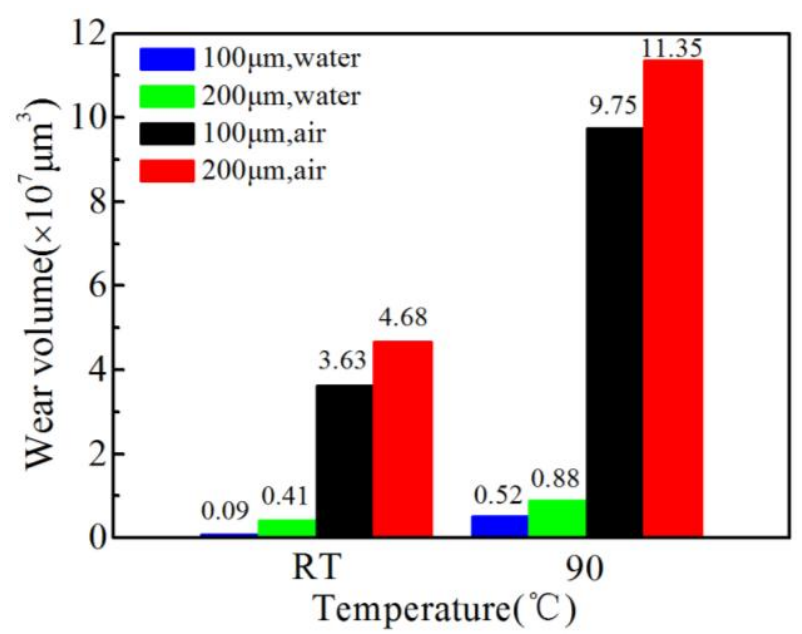

(b)

Fig. 12.Wear volume values of 690 alloy tube.

\section{Discussion}

In this present work, it can be concluded that the test environment directly determines the wear behavior and wear volume of 690 alloy tube against 405 stainless steel plate. Both in air and water environments, the wear volume increased from RT to $90{ }^{\circ} \mathrm{C}$ [Fig. 12(b)]. However, the wear volume value in air was much larger than that in water. Additional, the evolution of friction coefficient were different in air and in water, as shown in Fig. 13.

During the fretting process, the role played by the wear particles is significant and can strongly affect the friction and wear behaviors [24]. Wear particles changed the displacement accommodation in the contact zone and thus influenced the friction coefficient [25-26]. They can accelerate the wear process due to the formation of hard abrading oxides, or they can protect the surfaces due to reducing the interaction of the worn surfaces [27]. Besides, N. Diomidis et al. found that a large fluctuation in the friction coefficient corresponded to a rise and sudden fall in the position of the contact in consequence of the formation of wear particles and their ejection from the contact zone [24]. Therefore, the authors suggested that the different evolution of friction coefficient in air and in water has a close correlation to different behavior of wear particles.

In air, the removed materials were repeatedly ground and finally almost adhered to or expelled from the fretted zone (as shown in Fig. 14). The friction coefficient increased again to reach a quasi steady value after passing through a low point (1) (as shown in Fig. 13), in agreement with the SEM micrographs of wear scars [23]. On the contrary, when fretting in water, the wear particles were almost rejected and eventually accumulated at the edge of contact zone (as shown in Fig.5, Fig.6, 
Fig.10 and Fig.11). Compared with RT, $90{ }^{\circ} \mathrm{C}$ in water corresponded to high rate of oxidation (Fig.5, Fig.11 and Table 3), which led to a load-bearing oxidative layer formed in fretting zone, and therefore, the decrease of friction coefficient after 25000 cycles (point (2) in Fig. 13).

The wear particles not only affect the friction coefficient but also have a strong effect on the fretting affected area. Based on the results presented above, Fig. 15 illustrates a schematically the fretting affected area in air and in water. In air, the tube wear profile had characteristic "W" shape, which is different from the "U" shape observed fretting in water (as shown in Fig.7). A W-shape wear scar is usually observed in fretting tests [28-30], due to the maximum shear stress exhibited the outer part of contact zone, and combined with the wear particles hardly rejected from the center of contact zone in air. While the wear debris placed in the central contact zone protected the contact surfaces from being worn, the wear particles remained at the outer of contact zone accelerated wear due to their action as hard abrading oxides. Finally, the wear scar profile resembled a "W" shape. However, unlike in air, the damage in water was slight because of the occurrence of thin water film and the lack of wear particles in contact zone (Fig. 15(b)) [14]. During the early period of the fretting process, asperities were subjected to plastic deformation and abrasion after thin oxide film released [31], and hence wear damage on the base material was delayed. Meanwhile, the wear particles may be easily washed away from the contact zone (as shown in Fig. 6), and thus, reducing abrasive wear. A thin water film was later formed after several cycles. The water film seemed to protect the interfacial materials due to a reduction in the direct metal-metal contact and consequently reducing wear. Thus some pits remained unoxidized (as shown in Fig.10 and Fig.11), and wear particles were dispersedly distributed in the fretting zone. Ultimately, the wear surface was smoother, and homogeneous abrasion continues resulting in a $U$-shape wear scar in water. 


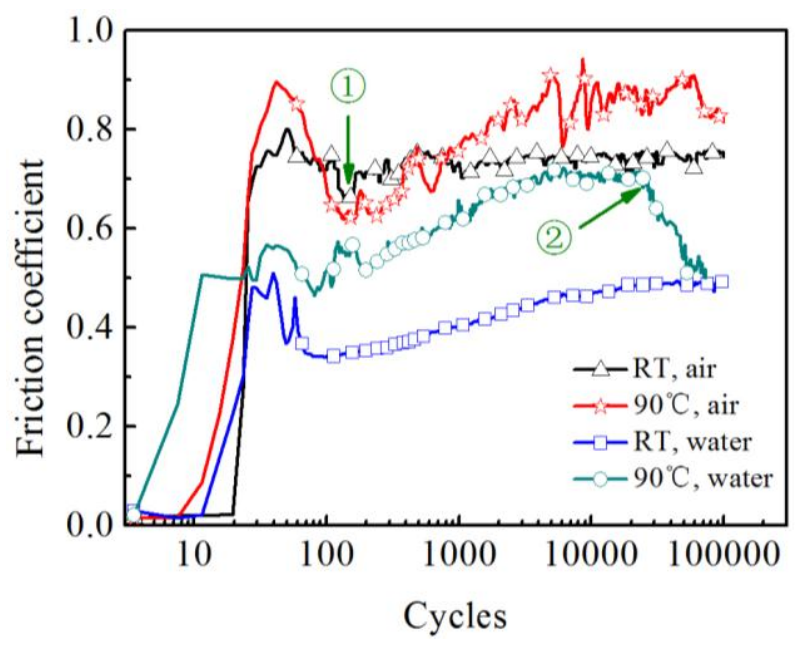

Fig. 13. Evolution of the coefficient of friction in air and in water, $D=100 \mu \mathrm{m}$.
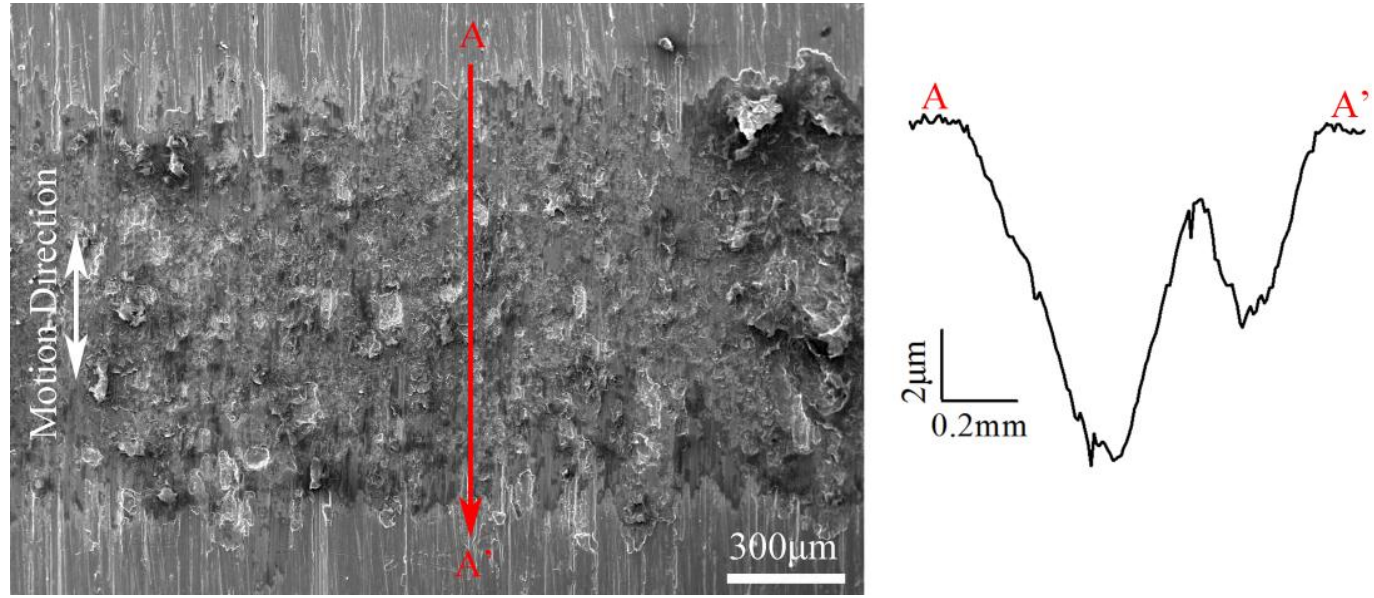

Fig. 14. SEM micrograph and profile micrograph of the worn plate fretted in room temperature air.
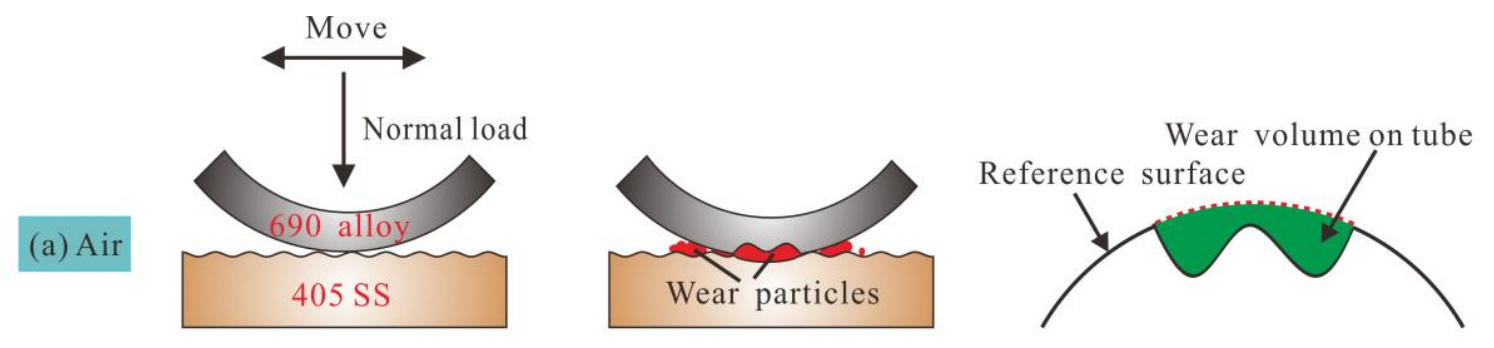

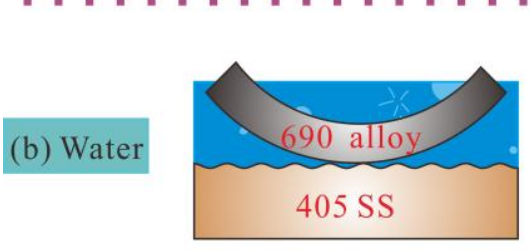

Initial

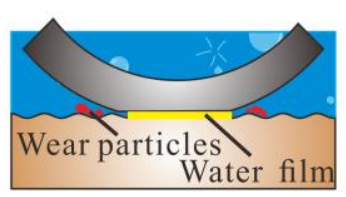

Final

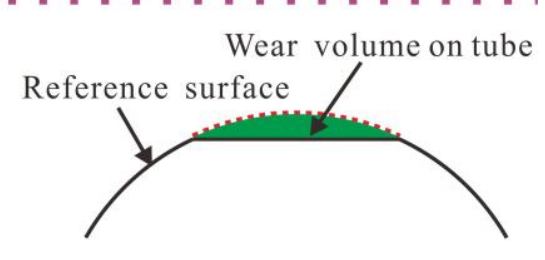

Profile

Fig. 15. Schematic diagram of fretting zone.

\section{Conclusions}

Fretting wear tests on 690 alloy tubes against 405 stainless steel plates were carried out in various water temperatures, and the results were compared with that under dry condition. The 
observation and analysis led to the following conclusions:

(a) The lubrication environment had a strong effect on the behavior of wear particles, which contributed to different wear behaviors and wear mechanisms. When fretting in water, the wear particles are ejected from the contact zone and accumulated at the edge of wear scar. Consequently, the wear scar showed a "U" shape profile along the fretting direction, while a "W" shape in air.

(b) The friction force and wear volume in air were considerably larger than those in water due to water lubrication. Meanwhile, the wear volume of 690 alloy tube showed a linear relationship to the water temperature. Above $60{ }^{\circ} \mathrm{C}$, more wear particles were generated and finally the friction coefficient decreased after 25000 cycles due to the formation of load-bearing oxidative layer.

(c) In water, the main wear mechanisms were delamination and abrasive wear, and the delamination wear increased as the temperature of water increased.

\section{Acknowledge}

The efforts of Helmi Attia, Mechanical Engineering Department, McGill University, in correcting the language of this paper are greatly appreciated. This study was supported by National Outstanding Youth Science Fund Project (51025519), National Science Foundation of China (51375407), Yangtze River Scholars and Innovation Team Development Plan (No. IRT1178), Shanghai Science and Technology Talent Program (14R21421500), and Large-scale advanced PWR major projects (2010Zx06004-18).

\section{Reference}

[1] Rubiolo PR, Young MY. On the factors affecting the fretting-wear risk of PWR fuel assemblies. Nucl Eng Des 2009; 239: 68-79.

[2] Jae Yong Yun, Myung Chul Park, Gyeong Su Shin, et al. Effects of amplitude and frequency on the wear mode change of Inconel 690 SG tube mated with SUS 409. Wear, 2014, 313:83-88.

[3] M. Del Giacco, A. Weisenburger, G. Mueller. Fretting corrosion in liquid lead of structural steels for lead-cooled nuclear systems: Preliminary study of the influence of temperature and time. Journal of Nuclear Materials, 2012, 423: 79-86.

[4] S.J. Zinkle, G.S. Was. Materials challenges in nuclear energy. Acta Materialia, 2013, $61: 735-758$.

[5] Yakai Zhao, In-Chul Choi, Yong-Jae Kim, et al. On the nanomechanical characteristics of thermally-treated alloy 690: Grain boundaries versus grain interior. Journal of Alloys and 
Compounds, 2014, 582: 141-145.

[6] Jae-do Kwon, Han-kyu Jeung, Il-sup Chung, et al. A study on fretting fatigue characteristics of Inconel 690 at high temperature. Tribology International, 2011, 44: 1483-1487.

[7] M. Helmi Attia. Fretting fatigue and wear damage of structural components in nuclear power stations-Fitness for service and life management perspective. Tribology International, 2006, 39: 1294-1304.

[8] Hee-Sang Shim, Myung Sik Choi, Deok Hyun Lee, et al. A prediction method for the general corrosion behavior of Alloy 690 steam generator tube using eddy current testing. Nuclear Engineering and Design, 2016, 297: 26-31.

[9] Jen-Hsien Hsu, Richard K. Brow. Corrosion of Inconel 690 and Inconel 693 in an iron phosphate glass melt. Corrosion Science, 2013, 75: 148-157.

[10] Do Haeng Hur, Deok Hyun Lee. Effect of solid solution carbon on stress corrosion cracking of Alloy 600 in a primary water at $360{ }^{\circ} \mathrm{C}$. Materials Science \& Engineering A, 2014, 603:129-133.

[11] Sung-Sik Kanga, Seong-Sik Hwangb, Hong-Pyo Kim, et al. The experience and analysis of vent pipe PWSCC (primary water stress corrosion cracking) in PWR vessel head penetration. Nuclear Engineering and Design, 2014, 269: 291-298.

[12] Zhanpeng Lu, Junjie Chen, Tetsuo Shoji, et al. Characterization of microstructure, local deformation and microchemistry in Alloy 690 heat-affected zone and stress corrosion cracking in high temperature water. Journal of Nuclear Materials, 2015, 465: 471-481.

[13] M.H. Zhu, Z.R. Zhou. On the mechanisms of various fretting wear modes. Tribology International, 2011, 44: 1378-1388.

[14] Chung I, Lee M. An experimental study on fretting wear behavior of cross-contacting Inconel 690 tubes. Nuclear Engineering and Design, 2011, 241(10): 4103-4110.

[15] Li J, Lu Y H. Effects of displacement amplitude on fretting wear behaviors and mechanism of Inconel 600 alloy. Wear, 2013, 304(1): 223-230.

[16] Jae Yong Yun, Gyeong Su Shin, Seon Jin Kim, et al. Effect of carbide size and spacing on the fretting wear behavior of Inconel 690 SG tube mated with SUS 409. Wear, 2015, 338-339: 252-257.

[17] Jie Li, Yonghao Lu, Haoyang Zhang, et al. Effect of grain size and hardness on fretting 
wear behavior of Inconel 600 alloys. Tribology International, 2015, 81: 215-222.

[18] Z.H. Wang, Y.H. Lu, J. Li, T. Shoji. Effect of pH value on the fretting wear behavior of Inconel 690 alloy. Tribology International , 2016, 95: 162-169.

[19] Zhang X Y, Ren P D, Peng J F, et al. Fretting wear behavior of Inconel 690 in hydrazine environments. Transactions of Nonferrous Metals Society of China, 2014, 24(2): 360-367.

[20] Ming-xue Shen, Xu-dong Peng, Xiang-kai Meng, et al. Fretting wear behaviour of acrylonitrile-butadiene rubber (NBR) for mechanical seal applications. Tribology International, doi:10.1016/j.triboint.2015.09.029

[21] Jie Li, Yonghao Lun, Haoyang Zhang, Long Xin. Effect of grain size and hardness on fretting wear behavior of Inconel 600 alloys. Tribology International, 2015, 81: 215-222.

[22] J.F. Zheng, J. Luo, M.H. Zhu, et al. Fretting wear behaviors of a railway axle steel. Tribology International, 2010, 43: 906-911.

[23] X. Mi, Z.B. Cai, M.H. Zhu, et al. Investigation of fretting wear behavior of Inconel 690 alloy in tube/plate contact configuration. Wear, 2015, 328-329:582-590.

[24] N. Diomidis, S. Mischler. Third body effects on friction and wear during fretting of steel contacts. Tribology International, 2011, 44: 1452-1460.

[25] Kayaba T, Iwabuchi A. Effect of the hardness of hardened steels and the action of oxides on fretting wear. Wear, 1981, 66:27-41.

[26] Ramesh R, Gnanamoorthy R. Effect of hardness on fretting wear behaviour of structural steel, En 24, against bearing steel, En 31. Materials and Design, 2007, 28:1447-1452.

[27] Warburton J. The fretting of mild steel in air. Wear, 1989, 131:365-386.

[28] Hyung-Kyu Kim, Seon-Jae Kim, Kyung-Ho Yoon, et al. Fretting wear of laterally supported tube. Wear, 2001, 250: 535-543.

[29] H.Y. Yu, Z.B. Cai, Z.R. Zhou, et al. Fretting behavior of cortical bone against titanium and its alloy. Wear, 2005, 259: 910-918.

[30] Zhen-bing Cai, Harry M. Meyer III, Jun Qu, et al. Comparison of the tribological behavior of steel-steel and Si3N4-steel contacts in lubricants with ZDDP or ionic liquid. Wear, 2014, 319: $172-183$.

[31] Suh N P. An overview of the delamination theory of wear. Wear, 1977, 44(1): 1-16. 